\title{
PRÉ-TRATAMENTO DE BAGAÇO E DE PALHA DE CANA DE AÇÚCAR VISANDO A DESLIGNIFICAÇÃO PARA PRODUÇÃO DE ETANOL
}

\author{
R. C.VIEIRA'1, D. P. C. ANTUNES', M. C. S. SILVA', R. M. R. G. ALMEIDA', V. G. BISPO ${ }^{1}$ \\ ${ }^{1}$ Universidade Federal de Alagoas, Centro de Tecnologia, Curso de Engenharia Química \\ E-mail para contato: rosana1correia@hotmail.com
}

\begin{abstract}
RESUMO - O Brasil gera aproximadamente 350 milhões de toneladas de resíduos lignocelulósicos por ano, entre estes estão o bagaço e a palha de cana-de-açúcar. Atualmente a queima do bagaço de cana de açúcar nas caldeiras das indústrias é um processo bem sucedido que torna as usinas autosuficientes em geração de energia, porém tais resíduos podem ser utilizados na produção de etanol. O objetivo deste trabalho foi investigar a produção de etanol $2 \mathrm{G}$ a partir do bagaço e palha de cana de açúcar, estudando a eficiência de diferentes tipos de pré-tratamentos: com ácido sulfúrico $\left(\mathrm{H}_{2} \mathrm{SO}_{4}\right)$, com hidróxido de sódio $(\mathrm{NaOH})$, orgânico e peróxido de hidrogênio $\left(\mathrm{H}_{2} \mathrm{O}_{2}\right)$ em meio básico. Portanto, a partir dos resultados obtidos que entre os pré-tratamentos do bagaço da cana-de-açúcar tanto o realizado com peróxido de hidrogênio, como o realizado com ácido sulfúrico tiveram um rendimento razoável de $60 \%$, enquanto que o pré-tratamento orgânico da palha da cana-de-açúcar foi o mais promissor, com rendimento de $85 \%$.
\end{abstract}

\section{INTRODUÇÃO}

O bagaço é um subproduto, remanescente da moagem dos colmos da cana-de-açúcar. É obtido na saída do último moinho das usinas e destilarias, e constitui um conjunto de partículas de diferentes tamanhos, que oscilam entre 1 e $25 \mathrm{~mm}$, apresentando um tamanho médio de 20 $\mathrm{mm}$, o qual depende fundamentalmente do número de moagens realizadas e do tamanho dos equipamentos. A morfologia do bagaço se encontra relacionada com a estrutura da cana, onde se encontram fibras exteriores do colmo ou da casca, feixes fibrovasculares e outras formas fibrosas que dão resistência ao colmo vegetal. (MACHADO, 2009)

A celulose é a matéria prima mais abundante e está presente na estrutura básica das células de todas as plantas. Ela é um polímero linear e pertence à função química dos hidratos, mais corretamente a dos glicídios. As moléculas de celulose tendem a formar pontes de hidrogênio intramoleculares (entre unidades de glicose da mesma molécula) e intermoleculares (entre as unidades de glicose de moléculas adjacentes). O primeiro tipo de interação é responsável por certa rigidez das cadeias unitárias, e o segundo pela formação da fibra vegetal (NASCIMENTO, 2007). 


\section{9 a 22 de outubro de 2014 \\ Florianópolis/SC}

A estrutura da celulose é formada por duas fases, uma cristalina (ordenada) e uma amorfa (desordenada). Essas regiões não possuem fronteiras bem definidas, mas parece haver uma transição de um arranjo ordenado das cadeias de celulose para um estado desordenado ou amorfo, no qual estas cadeias apresentam uma orientação menor. Na região cristalina a fibra tem maior resistência à tração, ao alongamento e à solvatação. Na região amorfa a fibra tem maior flexibilidade (GARZÓN FUENTES et al,. 2009).

Depois da celulose, a lignina é a substância orgânica polimérica mais abundante nas plantas. Ela está presente principalmente na lamela média e na parede secundária. A lignina é a substância que confere rigidez à parede das células (KIIPPER, 2009).

A distribuição da lignina nas células e nas plantas não é uniforme, assim como sua constituição em cada espécie não é a mesma. Devido ao fato de a lignina apresentar muitas variações (dependentes da espécie da planta, da parte da planta em que se encontra da época do ano em que é sintetizada, do solo, do clima e outros) e a grande dificuldade de se isolar a macromolécula sem que esta sofra alterações em sua estrutura original (degradação, condensação) não é possível formular sua estrutura química (GARZÓN FUENTES et al,. 2009).

Geralmente, é um polímero natural formado basicamente por unidades fenilproprano, ligadas entre si em diversas posições. A biossintese da lignina ocorre através da polimerização radical dos seus precursores: álcoois sinapílico, coniferílico o paracumarílico (GARZÓN , 2009).

Entre os passos cruciais na produção de etanol estão à hidrólise enzimática e a fermentação da celulose para a produção de etanol. A presença de lignina torna o acesso à celulose difícil, afetando a eficiência da hidrolise. O objetivo do pré-tratamento é remover ou modificar a estrutura da lignina para facilitar o ataque enzimático, evitando a degradação da celulose.

Os pré-tratamentos químicos podem ser definidos como técnicas que envolvem agentes químicos tais como ácidos, bases, solventes orgânicos. Um tratamento químico tem como objetivo aumentar a superfície do substrato por inchação das fibras e a modificação ou a remoção da hemicelulose e/ou da lignina para fazer a celulose mais accessível para hidrolise enzimática (Figura 1) (GÓMEZ, 2010).

Os pré-tratamentos ácidos consistem em tratar a biomassa com ácidos diluídos ou concentrados para conseguir a solubilização da hemicelulose, com o fim de obter uma celulose mais acessível. O pré-tratamento com ácido diluído consiste na imersão do material em uma solução de ácido de aproximadamente $4 \%(\mathrm{p} / \mathrm{p})$ e em seguida aquecer até atingir temperaturas na faixa de 140 a $200{ }^{\circ} \mathrm{C}$ por períodos de tempos curtos $(10 \mathrm{~min}-1 \mathrm{~h}$ ). Diferentes reações ocorrem durante os pré-tratamentos ácidos; uma delas é a hidrólise das hemiceluloses, especialmente das xilanas e das glicanas, dando origem à produção de compostos tóxicos para a fermentação como o furfural e hidroximetilfurfural (GÓMEZ, 2010). 


\section{9 a 22 de outubro de 2014 \\ Florianópolis/SC}

Uma vantagem do pré-tratamento ácido é a solubilização de hemicelulose, aumentando a acessibilidade da celulose para as enzimas. Entretanto, existe o risco de formação de produtos voláteis de degradação do carbono e estes, em muitos casos, diminuem a conversão a etanol. No entanto, produtos voláteis podem ser convertidos a metano. A condensação e a precipitação de componentes de lignina solubilizada é uma reação indesejada, uma vez que diminui a digestibilidade. Pré-tratamentos com ácido concentrado para a produção de etanol não são processos atrativos, devido ao grande risco de produção de componentes inibidores pela degradação de carboidratos (MACHADO, 2009).

Nos pré-tratamentos alcalinos geralmente utilizam soluções alcalinas diluídas em condições moderadas de operação, como por exemplo hidróxido de sódio $(\mathrm{NaOH})$, em termos de temperaturas e pressões, em comparação aos sistemas ácidos. O principal efeito do prétratamento consiste na remoção da lignina da biomassa. $\mathrm{O}$ álcalino, geralmente soda ou cal, tende a causar um inchamento da biomassa, levando a uma diminuição na cristalinidade do grau de polimerização da celulose. Também provoca uma quebra das ligações lignina-carboidrato, além de perturbações na estrutura da lignina (GÓMEZ, 2010).

Em alguns casos, o pré-tratamento pode ser conduzido à temperatura ambiente, porém demanda tempos reacionais elevados, da ordem de horas, dias ou semanas. Ao contrário dos prétratamentos ácidos, uma limitação ocorre porque algumas bases podem ser convertidas em sais irrecuperáveis ou incorporadas como sais na biomassa através das reações do pré-tratamento (GÓMEZ, 2010).

\section{MATERIAIS E MÉTODOS}

\subsection{Métodos Analíticos}

As análises realizadas para a caracterização do bagaço e da palha da cana-de-açúcar foram: fibra, pectina, cinzas, umidade, lipídeo, teste de acidez;

\subsection{Pré-tratamentos do Bagaço e Palha da Cana-de-açúcar:}

Pré-Tratamento com $\mathrm{H}_{2} \underline{\mathrm{O}}_{2}$ em meio básico: Pesou-se $1,00 \mathrm{~g}$ da amostra, posteriormente adicionou-se em $50 \mathrm{~mL}$ de água oxigenada $1 \%(\mathrm{v} / \mathrm{v})$. O pH desta suspensão foi ajustado em 11,5 com solução aquosa de hidróxido de sódio e foi deixada em agitação durante $24 \mathrm{~h}$. O material sólido foi posteriormente lavado com água destilada até pH neutro, seco até massa constante e mantido em dessecador.

Pré-tratamento com ácido sulfúrico: Foi pesado aproximadamente $1,00 \mathrm{~g}$ da amostra que foram tratados com $10 \mathrm{~mL}$ da solução contendo ácido sulfúrico $0,5 \%$, por 15 minutos à $150{ }^{\circ} \mathrm{C}$. Ao término de cada uma das reações o líquido reacional foi descartado e os resíduos restantes lavados com água destilada. As amostras foram secas em estufa a uma temperatura de $50^{\circ} \mathrm{C}$, pesadas em uma balança analítica e armazenadas na geladeira em potes plásticos identificados; 
Pré-tratamento com NaOH: Pesou-se $1 \mathrm{~g}$ das amostras e foram tratadas com $10 \mathrm{~mL}$ de $\mathrm{NaOH}$ $1 \mathrm{M}$, sendo submetidas à agitação de $150 \mathrm{rpm}$ durante $7 \mathrm{mim}$ a $50{ }^{\circ} \mathrm{C}$. A reação foi interrompida com a adição de $190 \mathrm{~mL}$ de água destilada. Em seguida, o material foi auto clavado por 15 minutos. Após a descompressão da autoclave, o conteúdo foi resfriado à temperatura ambiente, sendo a mistura reacional filtrada em papel filtro qualitativo. A polpa obtida foi colocada para secar em estufa a $60^{\circ} \mathrm{C}$.

Pré-tratamento orgânico: Foram pesados 2,0g da amostra e em seguida foram adicionados $100 \mathrm{~mL}$ de etanol $\left(96^{\circ} \mathrm{GL}\right)$ e $100 \mathrm{~mL}$ de acetona $(99,5 \%)$. Posteriormente foi acrescentado $0,5 \mathrm{~g}$ de sulfato de ferro III por peso da amostra seca (agente oxidante), e $160 \mathrm{~mL}$ de água para diluição do ácido sulfúrico concentrado. Acrescentou-se água para completar volume no recipiente até 400 $\mathrm{mL}$. Os recipientes foram colocados em autoclave e a reação mantida em autoclave a $121^{\circ} \mathrm{C}$ e 1 atm durante $60 \mathrm{~min}$.

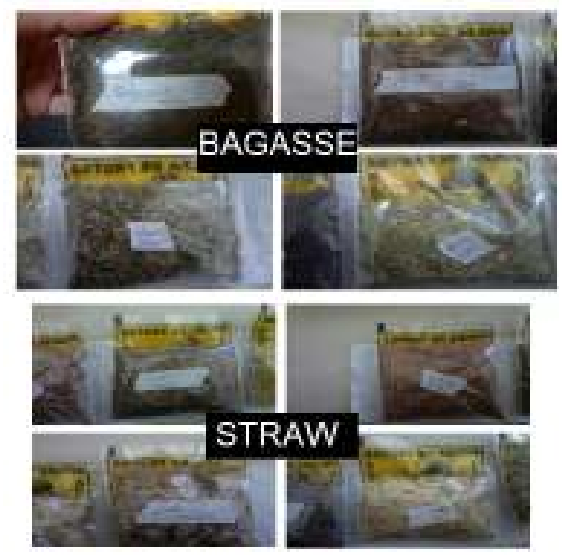

Figura 2: Pré-tratamento da palha e bagaço da cana-de-açúcar.

\subsection{Hidrólise da Celulose}

A hidrólise foi realizada em frascos de erlenmeyer de $250 \mathrm{~mL}$, contendo $48 \mathrm{~mL}$ de tampão acetato $(\mathrm{pH}=5), 2 \mathrm{~mL}$ de preparação comercial da enzima Celluclast e 2,5 g de matériaprima. Os frascos foram mantidos em mesa incubadora rotativa, tipo Shaker, à $50^{\circ} \mathrm{C}$ e $150 \mathrm{rpm}$, durante 72 horas. Posteriormente realizou-se a análise dos açúcares redutores para verificar a eficiência da hidrolise.

\section{RESULTADOS E DISCUSSÕES}

Após a realização dos métodos analíticos para a caracterização das amostras obtiveramse os dados encontrados da Tabela 1: 
Tabela 1 - Características físico-químicas do bagaço e palha da cana-de-açúcar

\begin{tabular}{|c|c|c|c|c|}
\hline Amostras & $\begin{array}{c}\text { Bagaço da cana- } \\
\text { de-açúcar }\end{array}$ & $\begin{array}{c}\text { Comparação: } \\
\text { Bagaço da } \\
\text { cana-de-açúcar }\end{array}$ & $\begin{array}{c}\text { Palha da cana- } \\
\text { de-açúcar }\end{array}$ & $\begin{array}{c}\text { Comparação: } \\
\text { Palha da cana- } \\
\text { de-açúcar }\end{array}$ \\
\hline \%Fibras & 39,92 & $41^{*}$ & 67,06 & $60^{*}$ \\
\hline \%Pectina & 1,84 & - & 1,94 & - \\
\hline \%Cinzas & 3,88 & $3,6^{* *}$ & 3,16 & $2,56^{* *}$ \\
\hline \%Umidade & 49,79 & $50^{* *}$ & 12,45 & $13,5^{* *}$ \\
\hline \%Lipídeos & 0,60 & - & 1,17 & - \\
\hline$\%$ \%cidez & 2,98 & - & 1,98 & - \\
\hline
\end{tabular}

*Fonte: CASTRO (2008); **Fonte: MENEZES (2012),

Os teores de fibra bruta encontrados foram os esperados, pois os resíduos utilizados são lignocelulósicos. Os teores de cinzas foram ótimos resultados, logo facilitou as etapas seguintes no projeto. O teor de umidade é relacionado os fatos das amostras encontrar-se em natura.

Após a realização da segunda fase do projeto, foram obtidos os devidos rendimentos, que se encontram na Tabela 2.

Tabela 2 - Rendimento após pré-tratamento do bagaço e palha da cana-de-açúcar.

\begin{tabular}{|l|c|c|}
\hline \multicolumn{1}{|c|}{ Pré-tratamento } & $\begin{array}{c}\text { Bagaço da cana- } \\
\text { de-açúcar }\end{array}$ & $\begin{array}{l}\text { Palha da cana-de- } \\
\text { açúcar }\end{array}$ \\
\hline $\mathrm{H}_{2} \mathrm{O}_{2}$ em meio básico & $\pm 60 \%$ & $\pm 75 \%$ \\
\hline Acido sulfúrico & $\pm 60 \%$ & $\pm 83 \%$ \\
\hline Orgânico & $\pm 54 \%$ & $\pm 85 \%$ \\
\hline Hidróxido de sódio & $\pm 48,33 \%$ & $\pm 56,33 \%$ \\
\hline
\end{tabular}

A terceira etapa do projeto foi a hidrolise e posteriormente a análise dos açúcares redutores, para a obtenção da quantidade de açúcar produzida pela enzima, consequentemente obtive-se a eficiência do pré-tratamento. 
A análise dos açúcares redutores foi realizada uilizando o método do espectrofotometrico e os dados obtidos na Tabela 3 foram calculados através do Gráfico 1 .

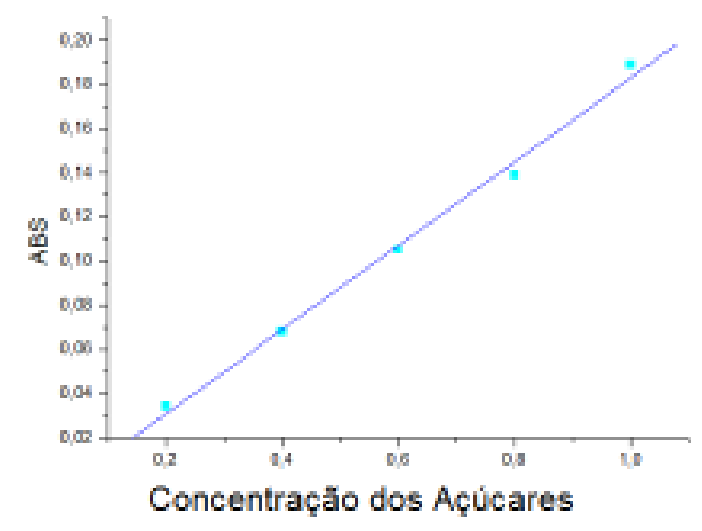

Gráfico 1 - Determinação de açúcares redutores.

Sendo a Equação 1 obtida através da linearização do Gráfico 1:

$$
\text { Abs }=0,1905 x \text { concentração }-0,0073
$$

Tabela 3 - Teor de açúcares redutores presente após hidrólise do bagaço e palha da cana-deaçúcar.

\begin{tabular}{|l|c|c|}
\hline \multicolumn{1}{|c|}{ Pré-tratamento } & $\begin{array}{c}\text { Bagaço da cana-de- } \\
\text { açúcar }\end{array}$ & $\begin{array}{c}\text { Palha da cana-de- } \\
\text { açúcar }\end{array}$ \\
\hline $\mathrm{H}_{2} \mathrm{O}_{2}$ em meio básico & $1,14 \mathrm{~g} / 100 \mathrm{~g}$ & $0,79 \mathrm{~g} / 100 \mathrm{~g}$ \\
\hline Acido sulfúrico & $1,35 \mathrm{~g} / 100 \mathrm{~g}$ & $1,03 \mathrm{~g} / 100 \mathrm{~g}$ \\
\hline Orgânico & $0,66 \mathrm{~g} / 100 \mathrm{~g}$ & $0,86 \mathrm{~g} / 100 \mathrm{~g}$ \\
\hline Hidróxido de sódio & $1,85 \mathrm{~g} / 100 \mathrm{~g}$ & $1,11 \mathrm{~g} / 100 \mathrm{~g}$ \\
\hline
\end{tabular}

\section{CONCLUSÕES}

Através dos dados expostos na Tabela 2 é possível observar que o pré-tratamento com melhor rendimento para a amostra da palha da cana-de-açúcar foi o pré-tratamento orgânico, aonde foi utilizado uma mistura de acetona e etanol. E para a amostra do bagaço da cana-deaçúcar foi o pré-tratamento ácido, aonde foi utilizado o ácido diluído. 


\section{9 a 22 de outubro de 2014 \\ Florianópolis/SC}

Todavia, observa-se que apesar do baixo rendimento, o pré-tratamento que realizou o melhor teor de AR foi o pré-tratamento básico, isto pode ser observado através da Tabela 3, onde se obtêm os valores do teor de açúcares redutores totais presentes após a realização da hidrólise.

Como não foi possível realizar um estudo mais detalhado após a etapa da hidrólise enzimática, devido à quebra do equipamento, não foi possível realizar a fermentação do material em estudo, que estabeleceria a comprovação de que o melhor pré-tratamento seria o prétratamento básico.

\section{REFERÊNCIAS}

CHRISTOFOLETTI, G. B. Estudo dos efeitos de etapas de pré-tratamento na hidrólise ácida de bagaço de cana-de-açúcar. São Carlos, 2010. Disponível em: $<$ http:/www.teses.usp.br/teses/disponiveis/88/88131/tde-13102010-211833/en.php>. Acessado dia 28 de dezembro de 2013;

GARZÓN, L. L. Fuentes. Determinação de dados cinéticos da deslignificação do bagaço de cana-de-açúcar e da hidrólise enzimática no pré-tratamento com hidróxido de cálcio. Campinas, SP: $\quad$ [s.n.], 2009. Disponível em: $<$ http://www.bibliotecadigital.unicamp.br/document/?code $=000465175>$ Acessado dia 04 de janeiro de 2014;

GÓMEZ, S. M. R. Pré-tratamento e Hidrólise Enzimática do Bagaço de Cana-de-açúcar . Campinas, SP: $\quad$ [s.n.], 2010. $\quad$ Disponível em: $<$ http://www.bibliotecadigital.unicamp.br/document/?code $=000771602>$. Acessado dia 26 de dezembro de 2013;

KIIPPER, P. G. Estudo da pré-hidrólise ácida do bagaço de cana-de-açúcar e fermentação alcoólica do mosto de xilose por Pachysolen tannophilus. Rio Claro : [s.n.], 2009. Disponível em: < http://www.acervodigital.unesp.br/handle/123456789/55960> Acessado dia 20 de janeiro de 2014;

ICIDCA - Instituto Cubano de Investigaciones de los Derivados de la Caña de Azúcar. Etanol celulósico: o bagaço da cana-deaçúcar como matéria-prima para a hidrólise. Derivatives Manual, Habana, Cuba (in Spanish, 1999. Dispónivel em: <http://www.novacana.com/estudos/etanolcelulosico-bagaco-cana-de-acucar-como-materia-prima-para-hidrolise241013/?print=1> Acessado em: 26 de janeiro de 2014;

MACHADO, D. de S. Seleção de fungos capazes de hidrolisar bagaço de canade-açucar prétratado. $\quad$ Piracicaba, 2009. Disponível em: www.teses.usp.br/teses/.../11/...09112009.../Denise_Machado.pdf $>$ Acessado dia 11 de janeiro de 2014;

NASCIMENTO, Renata Trajano. Ester Ribeiro Gouveia. Efeito do tipo de tratamento do bagaço de cana-de-açúcar na hidrólise enzimática. XV Congresso de Iniciação Científica da UFPE, 2007. 
Disponível

em:

$<$

http://www.contabeis.ufpe.br/propesq/images/conic/2007/CONIC_JOIC_2007\%20(E)/coni c/n _pibic/20/21216.pdf> Acessado dia 09 de janeiro de 2014;

CASTRO, L. B. B. N. OLIVEIRA, L. A. MOREIRA, R. F. MURTA, R.M. Bagaço de cana-deaçúcar para alimentação de ruminantes. Escola Agrotécnica Federal de Salinas, 2008. Disponível em: <http: // www. pubvet.com.br / artigos_det.asp?artigo=432>. Acessado dia 15 de junho de 2014;

MENESES, R. K. O. MENDES, M.R. ALVES, G.H.O. SANTOS, L.A. ROSA, C.V.G.S. SOUZA, J.E.A. BARBOSA, A.S.R. DIAS, A.B.A. MENEGHETTI, S.M.P. Município Alagoano para fins energético, 2012. Disponiveis em: <http://www.abq.org.br/entequi / 2012/trabalhos/ 50/50-400-13741.html>. Acessado no dia 15 de junho de 2014; 